\title{
BURNOUT SYNDROME AMONG MEDICAL COLLEGE FACULTIES IN CHENNAI- A CROSS-SECTIONAL STUDY
}

\author{
Sowmiya K. R1, Danshree A2, Balaji Arumugam³, Devipriya T4 \\ ${ }_{1}^{1}$ Associate Professor, Department of Community Medicine, Tagore Medical College and Hospital, Chennai. \\ 2Intern, Tagore Medical College and Hospital, Chennai. \\ 3 Professor and HOD, Department of Community Medicine, Tagore Medical College and Hospital, Chennai. \\ 4Intern, Tagore Medical College and Hospital, Chennai.
}

\section{ABSTRACT}

\section{BACKGROUND}

Burnout is a stress-induced problem commonly found among human service professionals which is characterised by emotional exhaustion, a reduced sense of personal accomplishment and depersonalisation. This study was undertaken to assess the professional burnout and its covariates among medical professionals working in a Medical College, Chennai.

\section{MATERIALS AND METHODS}

It is a cross-sectional study done among 250 faculties working in a private medical college in Chennai. The prevalence of burnout was assessed using self-administered Oldenburg's burnout inventory (OLBI), which is free to use and internationally validated. A pre-tested Structured Questionnaire was used to assess the factors associated with it and the coping strategies employed. Binary logistic regression analysis was done to calculate adjusted odds ratio to assess association between burnout and the covariates.

\section{RESULTS}

Among the 250 participants, 128 were women and 122 were men with the mean age of $31.9 \pm 10.8$ years. $42 \%$ belonged to medicine-allied fields, $36.4 \%$ surgery allied and $21.6 \%$ were from pre- and para-clinical department. Among the study group $27.2 \%$ experienced burnout, the majority being doctors in medicine allied fields (29.81\%). The study showed that prevalence of burnout was higher among women, those suffering from inadequate sleep, those who do not communicate effectively and those unable to deal with anger/ failures. Higher professional burnout was also seen among doctors undermined by colleagues or superiors and those who were unsatisfied with their income. In contrast, marriage seems to be a protective factor with those married having 0.78 times lesser risk of being burnt out.

\section{CONCLUSION}

Professional burnout is a serious issue, which unless properly addressed may impair their quality of life.

\section{KEYWORDS}

Professional, Job Stress, Anxiety, Mental Health, Teaching Faculty.

HOW TO CITE THIS ARTICLE: Sowmiya KR, Danshree A, Arumugam B, et al. Burnout syndrome among medical college faculties in Chennai- a cross-sectional study. J. Evolution Med. Dent. Sci. 2018;7(08):1016-1019, D0I: 10.14260/jemds/2018/232

\section{BACKGROUND}

In this age of globalisation, every job is stressful. But those in the medical profession have to deal with immense loads of stress on both the professional and personal front. Doctors have to cope with certain unavoidable stressors, such as the death of their patients or the inability to cure them or relieve them of their suffering. But there are certain workplace stressors such as work organisation, financial issues, administration, interference with family and social life, relationship with superiors and colleagues and work demand, $[1,2,3]$ which are major contributing factors towards an under-represented emerging lifestyle disease, i.e. the Burnout Syndrome. ${ }^{[4]}$

'Financial or Other Competing Interest': None.

Submission 10-01-2018, Peer Review 03-02-2018,

Acceptance 09-02-2018, Published 19-02-2018.

Corresponding Author:

Sowmiya K. $R$,

2G, Quanta Trinity,

18 West Road,

West CIT Nagar,

Chennai-600035.

E-mail: krs3012@gmail.com

DOI: $10.14260 /$ jemds $/ 2018 / 232$

\section{(c) (i) $(8)$}

Professor Christina Maslach was a pioneer in burnout research, devised "The Maslach Burnout Inventory" (MBI) and defined it as "a stress-induced problem commonly found among human service professionals, which is characterised by emotional exhaustion, a reduced sense of personal accomplishment and depersonalisation." [5]

Burnout is also defined as a feeling of hopelessness, inability in carrying out one's job effectively. It is a response to a chronic stressful working environment involving high expectations, inadequate resources and poor recognition.[6]

Stress in itself does not cause burnout, representing separate entities, but both concepts are strongly interrelated. Many workers have job stress but do not experience burnout, conversely no one will experience burnout without experiencing job stress. ${ }^{[6]}$

Stress is defined as an uncomfortable cognitive state resulting from exposure to a stressor that can result in psychological and physiological strain.[7] It is associated with a complex relationship between personal factors and external factors. Work-related stress is the response people may have when presented with work demands and pressures that are not matched to their knowledge and abilities, and which challenge their ability to cope. ${ }^{[8]}$

Burnout can badly affect one's performance at work ${ }^{[9]}$ and have detrimental effects on health and personal life. ${ }^{[10]}$ Due to 
its nature, the lack of awareness and our failure to detect it easily and quickly burnout can be a significant problem in the medical field. It needs to be addressed promptly, especially in India where the burden of healthcare is dependent upon a limited number of doctors, most of them overworked and underpaid.

Globalisation, modernisation, privatisation and liberalisation have brought tremendous improvements in the quality of life. At the same time they have had detrimental effects such as increasing demands of learning new skills, the need to adopt new types of work, pressure of higher productivity and quality of work, time pressure and hectic jobs, which in turn may produce burnout- particularly in rapidly developing countries like India.[11]

One such study done across India in 2016 with a sample of doctors shows high levels of burnout among entire population, about $65.8 \% .{ }^{[12]}$ It is a need of the hour to explore the prevalence of burnout among medical professionals, especially in a metropolitan city like Chennai. With this in mind, this study was done with the objective of assessing the prevalence of burnout among doctors in Chennai and to find out the associating factors and the preventive strategies adopted in overcoming it.

\section{MATERIALS AND METHODS}

This cross-sectional study was done among teaching faculties of various specialties working in a private medical college, Chennai, Southern India. The study was conducted during the period of three months (December 2016 to February 2017). The complete list of medical professionals working in the Medical College was obtained and a digital code was assigned to each one of them. After obtaining the Institutional Ethics Committee approval, the study was initiated among the medical college teachers. Oral informed consent was taken from all the participants. They were interviewed by a structured, pre-tested questionnaire. Demographic details, information suggestive of burnout and the factors associated with it were collected.

\section{Study Tool used for Professional Burnout}

The Oldenburg Burnout Inventory (OLBI), a self-administered questionnaire was used as the study instrument. It was chosen because it is free to use for non-commercial purposes, internationally validated and easy to answer by the study participants.[13,14,15]

The questionnaire assesses disengagement and exhaustion as two main features of burnout. There were sixteen questions in the questionnaire. Eight out of sixteen assess the exhaustion component and rest, the disengagement. Each question has four options and candidate has to select one, indicating the degree of agreement and score to the relevant answer is given as mentioned below. Calculations were done separately for both components. If the mean in both categories is more than 2.5 , they were considered to have burnout.[13,16,17]

\section{Data Analysis}

Results were given in mean and standard deviation. Differences between proportions of groups were tested for statistical significance using the chi-square test. Probability values less than 0.05 were considered to be as statistically significant. Binary logistic regression analysis was done to calculate adjusted odds ratio to assess association between burnout and the covariates. Analysis was done in IBM SPSS version 21.0 .

\section{RESULTS}

There were 261 teaching faculties, among which 7 opted to drop out of the study and 4 women faculty had gone on maternity leave making the sample size of 250 . Among the 250 medical teachers, 128 were women and 122 were men. The age of study population ranged from 23 years to 73 years with a mean age of $31.9 \pm 10.8$ years. The general demographics of the study group are given in Table 1.

\begin{tabular}{|c|c|c|c|}
\hline & & Number & $\mathbf{\%}$ \\
\hline \multirow{3}{*}{ Age Group } & $20-40$ years & 205 & 82 \\
\cline { 2 - 4 } & 41-60 years & 27 & 10.8 \\
\cline { 2 - 4 } & $>60$ years & 18 & 7.2 \\
\hline \multirow{3}{*}{ Sex } & Male & 122 & 48.8 \\
\cline { 2 - 4 } & Female & 128 & 51.2 \\
\hline \multirow{3}{*}{ Specialty } & Pre- and Para-Clinical & 54 & 21.6 \\
\cline { 2 - 4 } & Medicine Allied & 105 & 42 \\
\cline { 2 - 4 } & Surgery Allied & 91 & 36.4 \\
\hline Marital & Married & 123 & 51.2 \\
\cline { 2 - 4 } Status & Unmarried & 127 & 48.8 \\
\hline \multirow{2}{*}{$\begin{array}{c}\text { Occupation } \\
\text { of Spouse }\end{array}$} & Medico & 94 & 76.4 \\
\hline & Non-Medico & 29 & 23.6 \\
\hline \multicolumn{3}{|c|}{ Table 1. General Demographics } \\
\hline
\end{tabular}

\section{Prevalence of Burnout}

The prevalence of exhaustion was more common among the study group than disengagement as shown in Table 2 . The overall prevalence of burnout among the study population was $27.2 \%$.

\begin{tabular}{|c|c|c|}
\hline & Number & $\mathbf{\%}$ \\
\hline Exhaustion & & \\
\hline Yes & 116 & 46.4 \\
\hline No & 134 & 53.6 \\
\hline Disengagement & & \\
\hline Yes & 92 & 36.8 \\
\hline No & 158 & 63.2 \\
\hline Burnout & 68 & 27.2 \\
\hline Yes & 182 & 72.8 \\
\hline No & & \\
\hline Table 2. Prevalence of Burnout Syndrome \\
\hline
\end{tabular}

\section{Factors Associated with Burnout}

Among the study group $27.2 \%$ experienced burnout, the majority being medical professionals working in medicine allied specialties- General Medicine, Tuberculosis and Respiratory diseases, Dermatology, Venereology and Leprosy, and Psychiatry (29.81\%).

\section{Predictors of Burnout}

Logistic regression was used to find out the predictors of burnout. During the subgroup analysis, we discovered that women have 4 times [O.R- $3.9(1.16$ - 9.61)] greater risk than men in developing burnout syndrome. Workplace factors such as feeling undermined by their colleagues and being unsatisfied with their income have 2.5 times and 3 times risk, respectively. Those who feel their sleep is inadequate have 2.3 times more chances of developing burnout. In addition to 
workplace factors, our study has also discovered that the inherent personality of the person plays a major part in deciding whether they could develop burnout or not. Those unable to communicate effectively with others have a 5 times greater risk and those with poor anger management have a 2.8 times risk. In contrast marriage seems to be a protective factor, with those who are married having 0.78 times lesser risk of being burnt out. The following Table 3 enumerates the results.

\begin{tabular}{|c|c|c|}
\hline Predictors & $\begin{array}{c}\text { Adjusted Odds } \\
\text { Ratio (95\% CI) }\end{array}$ & P value \\
\hline Females & $3.9(1.16-9.61)$ & 0.05 \\
\hline Married & $0.78(0.12-0.78)$ & 0.02 \\
\hline Inadequate Sleep & $2.3(1.41-8.5)$ & 0.01 \\
\hline $\begin{array}{c}\text { Undermined by } \\
\text { Colleagues or Superiors }\end{array}$ & $2.5(1.1-7.3)$ & 0.02 \\
\hline $\begin{array}{c}\text { Unsatisfied with the } \\
\text { Income }\end{array}$ & $3.01(1.06-8.42)$ & 0.03 \\
\hline $\begin{array}{c}\text { Unable to Communicate } \\
\text { Effectively }\end{array}$ & $5.3(1.41-8.5)$ & 0.05 \\
\hline Poor Anger Management & $2.8(1.2-6.11)$ & 0.04 \\
\hline \multicolumn{2}{|c|}{ Table 3. Predictors of Burnout } \\
\hline \multicolumn{2}{|c|}{} \\
\hline
\end{tabular}

\section{DISCUSSION}

Among the 250 study participants, majority were women $(51.2 \%)$ and the rest were men (48.8\%). We used The Oldenburg Burnout Inventory, which assesses two important components of burnout i.e. exhaustion and disengagement. On conducting the study, we discovered that out of the 250 participants 68 (27.2) experienced burnout. Between the two components, more number of participants experienced exhaustion (46.4\%) than disengagement (36.8\%).

We discovered many studies while looking for literature which pointed to people in the service industry, especially doctors. Many studies have shown that Burnout has a high prevalence among practicing doctors and that one-third of physicians have experienced burnout at certain points throughout their careers. They describe it as that "Burnout" begins to appear during the medical school days itself, continuing on throughout the residency period and finally culminating in the daily life of practicing physicians, affecting both their professional and personal lives.

A study done among medical students in the USA suggests that the prevalence of burnout among them ranges between $31 \%$ and $49.6 \% .^{[7]}$ Another study done among residents showed that $50 \%$ and $76 \%$ of surgical and internal medicine residents are affected, respectively.[8] A study by Cohen et al found that at least one-third of Canadian medical residents from different specialties experience a stressful life. ${ }^{[9]}$ On the contrary, Lagasse et al report that $12.5 \%$ of medical residents scored positively on the three dimensions altogether.[10] Even higher rates were recorded in a study done among Lebanese residents.[11] A study like ours done in Galle, Sri Lanka, discovered that $20.6 \%$ of the doctors participated in the study had burnout.[18]

During the subgroup analysis, we discovered that women are at an astounding 4 times greater risk than men in developing burnout syndrome. Workplace factors such as feeling undermined by their colleagues and being unsatisfied with their income have 2.5 times and 3 times risk, respectively. Those who feel their sleep is inadequate have 2.3 times more chances of developing burnout. In addition to workplace factors, our study has also discovered that the inherent personality of the person plays a major part in deciding whether they could develop burnout or not. Those unable to communicate effectively with others have a whopping 5 times greater risk and those with poor anger management have an astounding 2.8 times risk. In contrast, marriage seems to be a protective factor with those who are married having 0.78 times lesser risk of being burnt out.

Thus, many International studies indicate higher levels of burnout compared to the results that we obtained. But our sample does not reflect the whole country. Rapid developments in the medical field, burgeoning competition among doctors right from their medical school days, PG preparation and workplace stress will affect these results. In addition to working at Teaching Medical Colleges, many doctors are also involved in private practice and hence its significance needs to be evaluated. Thus, our study has simply touched the tip of the iceberg that is Burnout and further studies are required to understand the full scope of this emerging lifestyle disease.

\section{CONCLUSION}

Burnout among doctors is a serious issue, which has not been getting the attention it deserves. With its devastating professional and personal consequences, it is an emerging lifestyle disease and needs to be addressed further. In contrast to previous studies, our study has discovered that the personal attitude of the doctor towards his work has a great effect on him/ her experiencing burnout. Hence, it is not only important to set up strategies to prevent workplace stress, but to also put in a framework to help people develop a positive attitude towards their work. We feel that this must begin during their medical school days itself. Our results also prove that sound sleep and yearly vacations go a long way to relieving doctors of their stress. This in turn enhances the quality of life of a single doctor, and its cumulative effect will definitely improve the overall quality of medical care provided.

\section{REFERENCES}

[1] Cubrilo-Turek M, Urek R, Turek S. Burnout syndrome-assessment of a stressful job among intensive care staff. Coll Antropol 2006;30(1):131-5.

[2] de Oliveira GS, Chang R, Fitzgerald PC, et al. The prevalence of burnout and depression and their association with adherence to safety and practice standards: a survey of United States anesthesiology trainees. Anesth Analg 2013;117(1):182-93.

[3] Eckleberry-Hunt J, Lick D, Boura J, et al. An exploratory study of resident burnout and wellness. Acad Med 2009;84(2):269-77.

[4] Selmanovic S, Ramic E, Pranjic N, et al. Stress at work and burnout syndrome in hospital doctors. Med Arh 2011;65(4):221-4.

[5] Pines A, Maslach C. Characteristics of staff burnout in mental health setting. Psychiatric Services 1978;29(4):233-7. 
[6] Caton DJ, Grossnickle WF, Cope JG, et al. Burnout and stress among employers at a state institution for mentally retarded persons. American Journal on Mental Retardation 1988;93(3):300-4.

[7] Hendrix WH, Summers TP, Leap TL, et al. Antecendents and organizational effectiveness outcomes of employee stress and health. In Crandall, R, Perrewe PL. (eds). Occupational stress. Washington DC: Taylor \& Francis, 1995:73-92.

[8] Work organization \& stress. Protecting workers health series no: $\quad 3 . \quad$ Available in: www.who.int/occupational_health/publications/en/o ehstress.pdf. Last accessed on March 2017.

[9] Suñer-Soler R, Grau-Martín A, Flichtentrei D, et al. The consequences of burnout syndrome among healthcare professionals in Spain and Spanish speaking Latin American countries. Burnout Research 2014;1(2):829.

[10] Shanafelt TD, Boone S, Tan L, et al. Burnout and satisfaction with work-life balance among US physicians relative to the general US population. Arch Intern Med 2012;172(18):1377-85.

[11] Kulkarni GK. Burnout. Indian Journal of Occupational and Environmental Medicine 2006;10(1):3-4.

[12] Langade D, Modi PD, Sidhwa YF, et al. Burnout syndrome among medical practitioners across India: a questionnaire-based survey. Cureus 2016;8(9):e771.
[13] Demerouti E, Bakker AB, Vardakou I, et al. The convergent validity of two burnout instruments. European Journal of Psychological Assessment 2003;19(1):12-23.

[14] Halbesleben JRB, Demerouti E. The construct validity of an alternative measure of burnout: investigating the English translation of the olden-burg burnout inventory. Work and Stress 2005;19(3):208-20.

[15] Halbesleben JR. The role of exhaustion and workarounds in predicting occupational injuries: a cross-lagged panel study of health care professionals. J Occup Health Psychol 2010;15(1):1-16.

[16] Demerouti E, Bakker AB. The oldenburg Burnout inventory: a good alternative to measure burnout and engagement. In: Halbesleben J. (eds). Handbook of stress and burnout in health care. Hauppauge, NY: Nova Science Publishers, pp 65-78.

[17] Demerouti E, Bakker AB, Nachreiner F, et al. The job demands-resources model of burnout. J Appl Psychol 2001;86(3):499-512.

[18] Vithanage AVDLA, De Silva PV, Lekamwasam JDVC. Prevalence of burnout among doctors in teaching hospitals in Galle Sri Lanka. European Journal of Preventive Medicine. Special Issue: New Frontiers of Public Health from the Pearl of Indian Ocean, Sri Lanka. 2015;3(2-1):1-4. 